\title{
Remedial Brushless AC Operation of Fault-Tolerant Doubly Salient Permanent-Magnet Motor Drives
}

\author{
Wenxiang Zhao, Member, IEEE, K. T. Chau, Senior Member, IEEE, Ming Cheng, Senior Member, IEEE, \\ Jinghua Ji, and Xiaoyong Zhu, Member, IEEE
}

\begin{abstract}
The doubly salient permanent-magnet (DSPM) machine is a new class of stator-PM brushless machines, which inherently offers the fault-tolerant feature. In this paper, a new operation strategy is proposed and implemented for fault-tolerant DSPM motor drives. The key is to operate the DSPM motor drive in a remedial brushless ac (BLAC) mode under the open-circuit fault condition, while operating in the conventional brushless dc mode under normal condition. Both cosimulation and experimental results confirm that the proposed remedial BLAC operation can maintain the average torque, reduce the torque ripple, and retain the self-starting capability under the open-circuit fault.
\end{abstract}

Index Terms-Brushless ac (BLAC), brushless dc (BLDC), cosimulation, fault-tolerant machine, permanent-magnet (PM) machine.

\section{INTRODUCTION}

$\mathbf{T}$ HERE ARE many applications in which the reliability of motor drives is utmost important. Thus, the fault-tolerant capability of motor drives is becoming attractive. A number of studies have investigated various types of motor drives and their fault-tolerant features for some critical applications. The switched-reluctance (SR) motor drive has gained attention due to its rugged construction and fault-tolerant capability [1]. However, it still suffers from the drawback of low power density. Permanent-magnet (PM) brushless motor drives are attracting extensive attention due to their high power density and high efficiency [2]. Some fault-tolerant PM brushless machines having PMs in the rotor (the so-called rotor-PM brushless machines) were proposed [3]. An optimal torquecontrol strategy for these machines was also reported [4].

Manuscript received November 21, 2008; revised March 16, 2009; accepted May 6, 2009. Date of publication October 9, 2009; date of current version May 12, 2010. This work was supported in part by the National Natural Science Foundation of China through Grants under Projects 50729702, 50807022, 60974060, and 50907031, by the Aeronautical Science Foundation of China through a Grant under Project 20080769007, and by the Research Grants Council, Hong Kong Special Administrative Region, China, under Grant HKU7105/07E.

W. Zhao is with the School of Electrical and Information Engineering, Jiangsu University, Zhenjiang 212013, China (e-mail: zwx@ujs.edu.cn). $\mathrm{He}$ was with the Department of Electrical and Electronic Engineering, The University of Hong Kong, Hong Kong, and also with the School of Electrical Engineering, Southeast University, Nanjing 210096, China.

K. T. Chau is with the Department of Electrical and Electronic Engineering, The University of Hong Kong, Hong Kong (e-mail: ktchau @ eee.hku.hk).

M. Cheng is with the School of Electrical Engineering, Southeast University, Nanjing 210096, China (e-mail: mcheng@ seu.edu.cn).

J. Ji and X. Zhu are with the School of Electrical and Information Engineering, Jiangsu University, Zhenjiang 212013, China (e-mail: jjh@ujs.edu.cn; zxyff@ujs.edu.cn).

Color versions of one or more of the figures in this paper are available online at http://ieeexplore.iee.org.

Digital Object Identifier 10.1109/TIE.2009.2033824
In [5]-[8], some compensation techniques for open-circuited fault were proposed to improve the fault-tolerant performance of multiphase rotor-PM brushless motor drives. Nevertheless, these rotor-PM brushless motor drives inherently suffer from the problem of poor thermal dissipation in the rotor [9], which adversely affects the characteristics of PMs and, hence, the reliability of motor drives.

In recent years, a new class of PM brushless machines, namely, the doubly salient PM (DSPM) machine, has received wide attention [10]-[12]. This DSPM machine is a kind of stator-PM brushless machines with all PMs located in the stator and offers the merits of high power density, good mechanical integrity, and freedom from the thermal-dissipation problem [13], [14]. Very recently, it has been identified that a fourphase 8/6-pole DSPM motor drive can inherently offer the fault-tolerant operation under the phase-winding short-circuit fault and the power-switch open-circuit fault [15]. Therefore, a simple compensating strategy, namely, doubling the phase current in one of the healthy phases, has been proposed to supplement the average torque under the open-circuit fault. However, it cannot maintain the average torque that was produced at normal operation and suffers from serious unbalanced operation, causing high torque ripple.

Compared with the four-phase 8/6-pole DSPM motor, the three-phase 12/8-pole DSPM motor inherently possesses higher power density and lower torque ripple, while requiring simpler gate driving and inverter topology [16]. However, the corresponding adverse effect under the open-circuit fault will be more serious, and the performance of the aforementioned simple compensating strategy will be even worse.

The purpose of this paper is to propose and implement a new operation strategy for fault-tolerant DSPM motor drives, hence retaining the same average torque while maintaining balanced operation under the open-circuit fault. Rather than using a fourphase DSPM motor, a three-phase 12/8-pole DSPM motor is purposely adopted to amplify the effect of an open-circuit fault.

\section{DSPM MOTOR}

Fig. 1 shows the structure of the three-phase 12/8-pole DSPM motor, which has 12 salient poles in the stator, eight salient poles in the rotor, three-phase armature windings in the stator, and 4 PM poles in the stator. This motor actually incorporates the merits of both the SR motor and the PM brushless motor.

1) Similar to the SR motor, the DSPM motor has no PMs, brushes, or windings in the rotor, thus offering high 


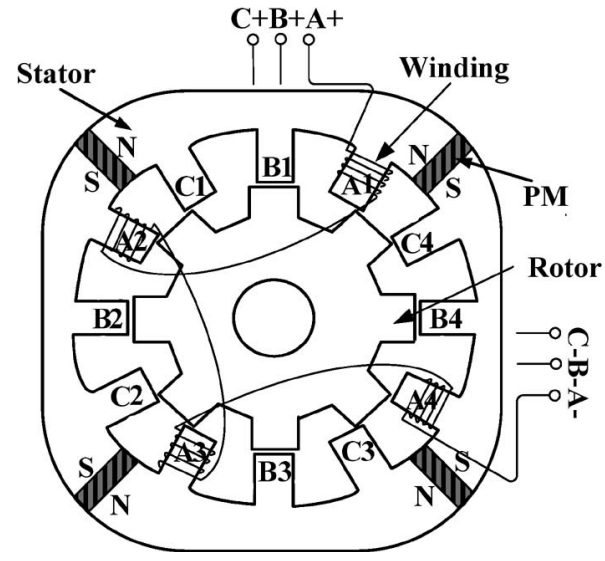

Fig. 1. Structure of three-phase 12/8-pole DSPM motor.

mechanical robustness and, hence, high reliability for high-speed operation.

2) Similar to the PM brushless motor, the air-gap flux is mainly excited by high-energy PMs, leading to the retention of the merits of high efficiency and power density.

3) Different from the traditional rotor-PM brushless motor, the DSPM motor arranges all PMs in the stator, thus eliminating the problem of thermal dissipation which adversely affects the characteristics of PMs.

4) Similar to the SR motor, the DSPM motor possesses the feature of independent electric and magnetic circuits among phases, thus offering the possibility of independent control and operation among phases. This feature is particularly important for fault-tolerant operation.

\section{BRUSHLESS DC AND AC OPERATIONS}

The proposed strategy involves two steps. First, before the occurrence of an open-circuit fault, the torque-equivalent brushless ac (BLAC) operation is derived, which can offer the same torque as the brushless dc (BLDC) operation. Second, the relationship between the torque-equivalent BLAC operation before the fault and the remedial BLAC operation after the fault is derived. Consequently, the required magnitudes and phase angles of the healthy phase currents can be deduced.

\section{A. Normal BLDC Operation}

Having a trapezoidal back electromotive force (EMF), the DSPM motor is inherently suitable for BLDC operation under normal condition, thus maximizing the torque or power density [17]. Fig. 2 shows the conventional BLDC mode of operation, namely, the $120^{\circ}$ conduction. In this operation mode, the armature current of phase- $p(p=a, b, c)$ can be expressed as

$$
i_{p}= \begin{cases}0, & 0 \leq \theta_{r}<\theta_{\text {on }}^{+} \\ I_{m}, & \theta_{\text {on }}^{+} \leq \theta_{r}<\theta_{\text {off }}^{+} \\ 0, & \theta_{\text {off }}^{+} \leq \theta_{r}<\theta_{\text {on }}^{-} \\ -I_{m}, & \theta_{\text {on }}^{-} \leq \theta_{r}<\theta_{\text {off }}^{-} \\ 0, & \theta_{\text {off }}^{-} \leq \theta_{r} \leq \theta_{\mathrm{rp}}\end{cases}
$$

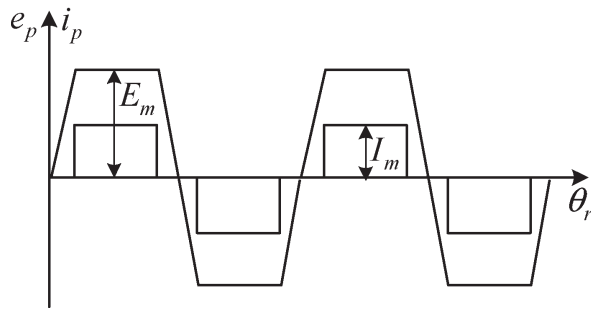

Fig. 2. Normal BLDC operation under trapezoidal back EMF.

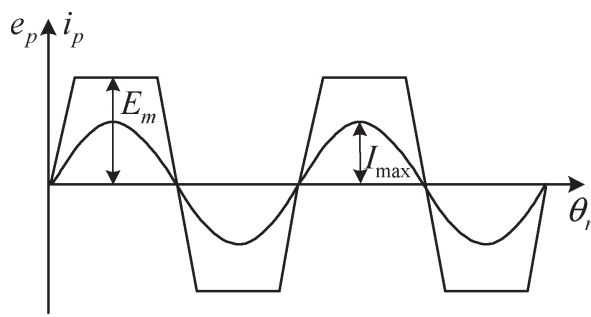

Fig. 3. BLAC operation under trapezoidal back EMF.

where $\theta_{\text {on }}^{+}, \theta_{\text {off }}^{+}, \theta_{\text {on }}^{-}$, and $\theta_{\text {off }}^{-}$are the positive turn-on, positive turn-off, negative turn-on, and negative turn-off angles, and $\theta_{\mathrm{rp}}$ is the rotor pitch. For the three-phase 12/8-pole DSPM motor, $\theta_{\mathrm{rp}}$ is equal to $45^{\circ}$ in mechanical angle, and the corresponding turn-on and turn-off regions are $\left(4^{\circ}-19^{\circ}\right.$ and $\left.26^{\circ}-41^{\circ}\right)$ and $\left(0^{\circ}-4^{\circ}, 19^{\circ}-26^{\circ}\right.$, and $\left.41^{\circ}-45^{\circ}\right)$, respectively.

Because of the PMs located in the stator, the motor torque is predominantly resulted from the PM excitation torque, whereas the reluctance torque is negligible. Therefore, the electromagnetic torque in the BLDC mode $T_{\mathrm{N} \_}$BLDC can be expressed as

$$
T_{\mathrm{N} \_ \text {BLDC }}=\frac{2 E_{m} I_{m}}{\omega_{r}}
$$

where $\omega_{r}$ is the electrical angular velocity, $E_{m}$ is the amplitude of the trapezoidal back EMF, and $I_{m}$ is the amplitude of the rectangular current.

\section{B. Torque-Equivalent BLAC Operation}

Traditionally, the DSPM motor adopts the BLAC operation only when its back-EMF waveform is sinusoidal. Such sinusoidal back EMF can be realized by rotor skewing, but with the sacrifice of EMF magnitude. Recently, it has been revealed that a trapezoidal back-EMF PM motor can operate in the BLAC mode to produce the same torque as in the BLDC mode [18]. Therefore, the torque-equivalent BLAC operation of the DSPM motor is used as an intermediate step to deduce the remedial BLAC operation.

Fig. 3 shows the BLAC operation for a conventional DSPM motor. For the three-phase 12/8-pole one, the phase currents are given by

$$
\left\{\begin{array}{l}
i_{a}=I_{\max } \sin (\omega t) \\
i_{b}=I_{\max } \sin (\omega t+2 \pi / 3) \\
i_{c}=I_{\max } \sin (\omega t-2 \pi / 3)
\end{array}\right.
$$


where $I_{\max }$ is the maximum value of the phase current. Therefore, the total electromagnetic torque $T_{\mathrm{N} \_B L A C}$ can be expressed as

$$
T_{\mathrm{N} \_ \text {BLAC }}=\frac{3 E_{m 1} I_{\max }}{2 \omega_{r}}
$$

where $E_{m 1}$ is the amplitude of the fundamental back EMF. By applying harmonic analysis to the trapezoidal back-EMF waveform, it yields

$$
\frac{E_{m 1}}{E_{m}}=1.216
$$

In order to create the same torque under the BLDC and BLAC modes, (2) is equated to (4). Then, by using (5), it deduces

$$
I_{\max }=1.096 I_{m}
$$

Thus, the torque-equivalent phase currents can be obtained as

$$
\left\{\begin{array}{l}
i_{a}=1.096 I_{m} \sin (\omega t) \\
i_{b}=1.096 I_{m} \sin (\omega t+2 \pi / 3) \\
i_{c}=1.096 I_{m} \sin (\omega t-2 \pi / 3) .
\end{array}\right.
$$

\section{Remedial BLAC Operation}

In case the motor drive is under fault, the faulty phase can be shut off and the remaining phases can continue operation. Thus, proper fault detectors need to be employed. Detailed discussions on the fault detectors for motor drives have been studied in [19] and [20]. This work focuses on how to develop a remedial control method to improve the fault-tolerant performance of DSPM motor drives under the open-circuit fault.

Based on the aforementioned torque-equivalent BLAC operation, the conventional DSPM motor can run in the BLAC mode to offer the same output torque as in the BLDC mode. Then, the effect of unbalanced operation can be overcome by keeping the magnetomotive force (MMF) produced by the healthy phases unchanged [6] between the torque-equivalent BLAC operation (all three phases are healthy) and the remedial BLAC operation (one phase is faulty while two phases are healthy).

Under the torque-equivalent BLAC operation, as described by (7), the total MMF is the sum of all three-phase MMFs, as given by

$$
M M F=M M F_{a}+M M F_{b}+M M F_{c}=N i_{a}+\alpha N i_{b}+\alpha^{2} N i_{c}
$$

where $\alpha=1 \angle 120^{\circ}$ and $N$ is the number of turns per phase. When phase- $\mathrm{A}$ is open circuited, the phase-A current vanishes so that the total MMF is contributed by the sum of phase- $\mathrm{B}$ and phase-C MMFs

$$
M M F^{\prime}=M M F_{b}^{\prime}+M M F_{c}^{\prime}=\alpha N i_{b}^{\prime}+\alpha^{2} N i_{c}^{\prime} .
$$

In order to maintain the output torque and regulate the unbalanced operation after the open-circuit fault, (8) is equated

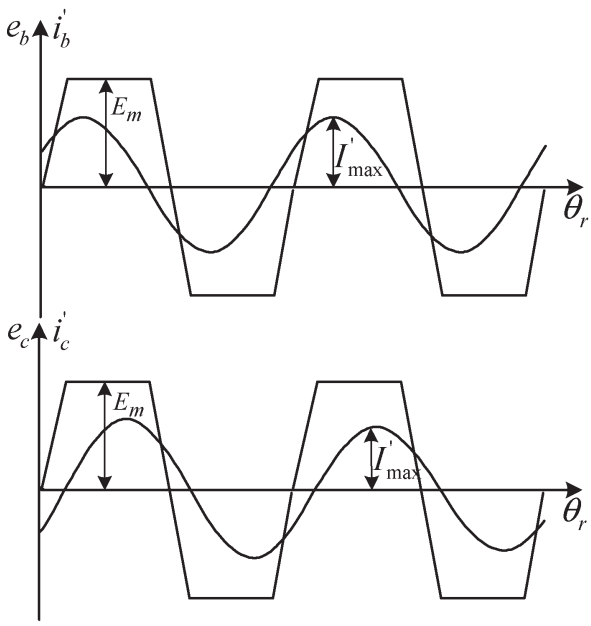

Fig. 4. Remedial BLAC operation under open-circuit fault.

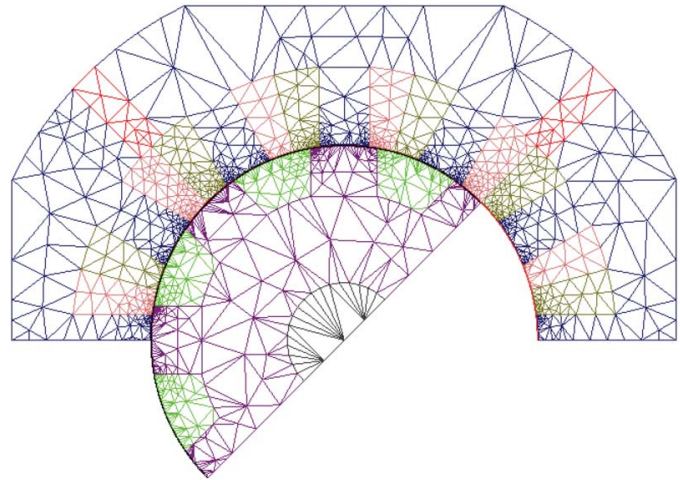

Fig. 5. Generated mesh of FEA model.

to (9). Then, by using (7), the currents of the healthy phases can be derived and expressed as

$$
\left\{\begin{array}{l}
i_{a}^{\prime}=0 \\
i_{b}^{\prime}=1.9 I_{m} \sin (\omega t+5 \pi / 6) \\
i_{c}^{\prime}=1.9 I_{m} \sin (\omega t-5 \pi / 6) .
\end{array}\right.
$$

Fig. 4 shows the proposed remedial BLAC operation of the DSPM motor after the loss of phase-A. Of course, a similar operation can be applied to the loss of phase-B or phase-C. It can be seen that, during the loss of phase-A, the remedial strategy is achieved by operating in the $180^{\circ}$ BLAC mode, rather than in the $120^{\circ}$ BLDC mode. Furthermore, the phase-B current is shifted forward by $30^{\circ}$ in electrical angle while the phase-C current is shifted backward by $30^{\circ}$, and their amplitude is scaled by 1.9 times the magnitude in the BLDC mode.

\section{Cosimulation Results}

In order to assess the aforementioned normal and faulty operations of the DSPM motor drive, the cosimulation technique is adopted in which the magnetic circuit and the electric circuit are coupled in the time domain, thus providing the convenience of system-level simulation [15], [21]. The modeling tools for the cosimulation are composed of two separate packages, namely, the magnetic solver Maxwell 2-D and the circuit solver Simplorer. The magnetic solver performs 


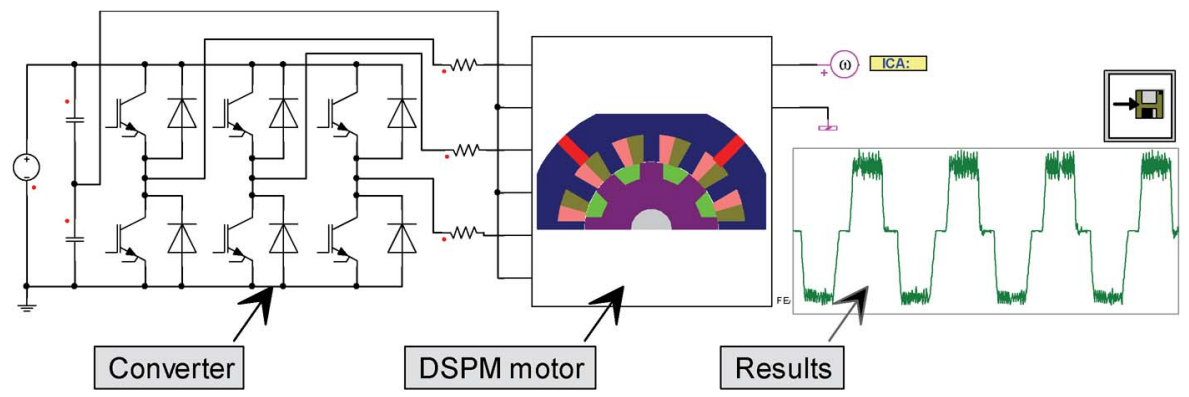

Fig. 6. Cosimulation model of DSPM motor drive.

finite-element analysis (FEA) of the DSPM motor, while the circuit solver performs electric-circuit analysis of the power converter. At each cosimulation time step, both the magnetic and circuit solvers exchange the calculated data, and the results produced by one solver will be exported to another solver in the next step. Consequently, the system performances can be accurately simulated.

Since the three-phase 12/8-pole DSPM motor is symmetrical in structure, only one half of the motor needs to be modeled for FEA. Fig. 5 shows the corresponding generated mesh. Then, the cosimulation model of the DSPM motor drive can be formulated as shown in Fig. 6, which consists of the power converter, the DSPM motor, and the simulated results.

To meet the requirement of independent control and operation among phases for the fault-tolerant DSPM motor drive, the neutral point of phase windings in the motor is connected to the midpoint of the dc link. This midpoint can be easily created by simply splitting the capacitor bank into two equal sections. During normal operation, there is no current flowing through the neutral of the DSPM motor. When one of the phases is under open-circuit fault, those healthy phases retain operation while the neural current exists.

To quantitatively evaluate the performances of the DSPM motor drive before and after fault, the average torque value and the torque-ripple level are useful while measurable parameters. Therefore, the torque-ripple factor is defined as

$$
K_{T}=\frac{T_{\max }-T_{\min }}{T_{\mathrm{av}}} \times 100 \%
$$

where $T_{\max }, T_{\min }$, and $T_{\mathrm{av}}$ are the maximum, minimum, and average values of the output torque, respectively.

During normal operation, the DSPM motor drive operates in the BLDC mode. Based on cosimulation, the motor current and torque waveforms are obtained, as shown in Fig. 7. It can be seen that the current waveform is rectangular and the corresponding $T_{\mathrm{av}}$ and $K_{T}$ of the motor drive are $2.94 \mathrm{~N} \cdot \mathrm{m}$ and $102.3 \%$, respectively. It should be noted that the torque ripple is caused by the phase-current commutations when the current is transferred from an off-going phase to the next oncoming phase at the end of each $60^{\circ}$ interval.

In the event of an open-circuit fault, one phase is lost and the other two phases continue operation. Without taking any remedial action, the torque waveform of this DSPM motor drive is shown in Fig. 8. It can be found that the motor drive suffers from a significant loss of torque, namely, $T_{\mathrm{av}}$ is $1.94 \mathrm{~N} \cdot \mathrm{m}$ which is only $66 \%$ of the normal average torque. Furthermore,

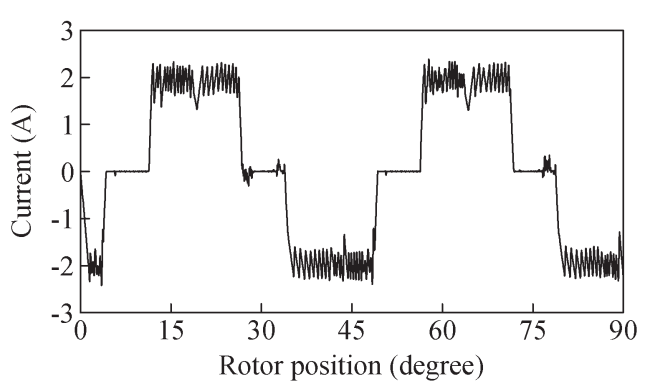

(a)

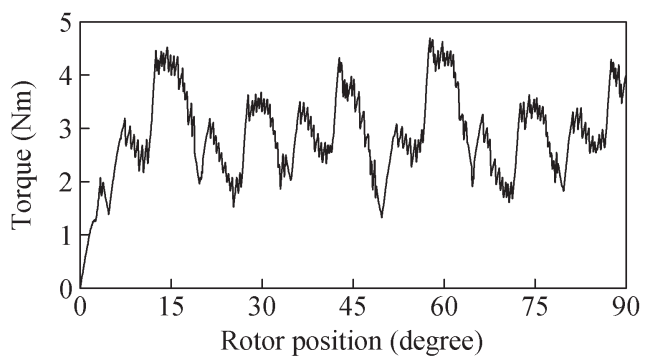

(b)

Fig. 7. Waveforms at normal BLDC operation. (a) Current. (b) Torque.

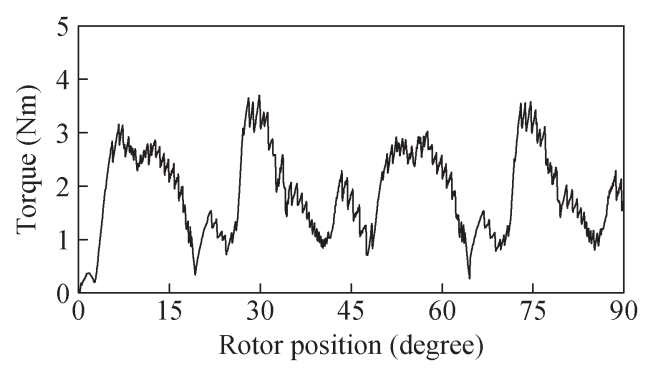

Fig. 8. Torque waveform at faulty BLDC operation.

the torque ripple under fault is significantly worsening, namely, $K_{T}$ is $156.3 \%$ which is $54 \%$ larger than the normal torqueripple factor.

In order to verify that the aforementioned torque-equivalent BLAC operation can offer the same torque as the normal BLDC operation, the current and torque waveforms are simulated by using (7). As shown in Fig. 9, it can be seen that the three-phase current waveforms are sinusoidal and that the corresponding $T_{\mathrm{av}}$ and $K_{T}$ are $3 \mathrm{~N} \cdot \mathrm{m}$ and $100.3 \%$, respectively. Compared with the values $\left(T_{\mathrm{av}}=2.94 \mathrm{~N} \cdot \mathrm{m}\right.$ and $K_{T}=$ $102.3 \%$ ) at BLDC operation, it confirms that their torque performances are practically the same. The slight discrepancies are 


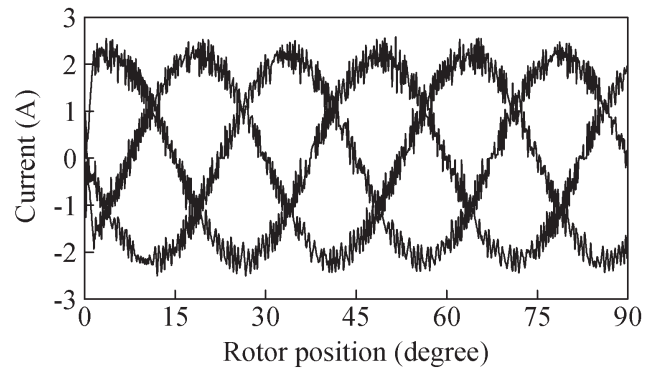

(a)

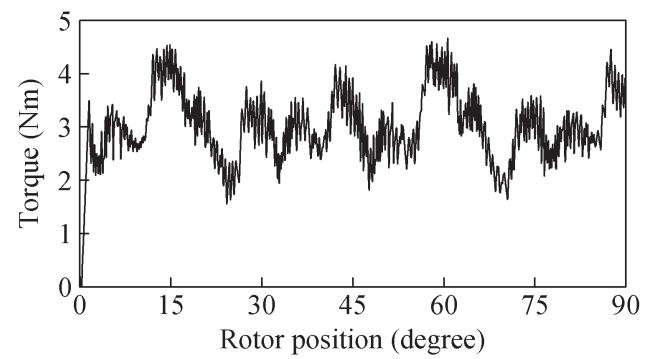

(b)

Fig. 9. Waveforms at torque-equivalent BLAC operation. (a) Current. (b) Torque.

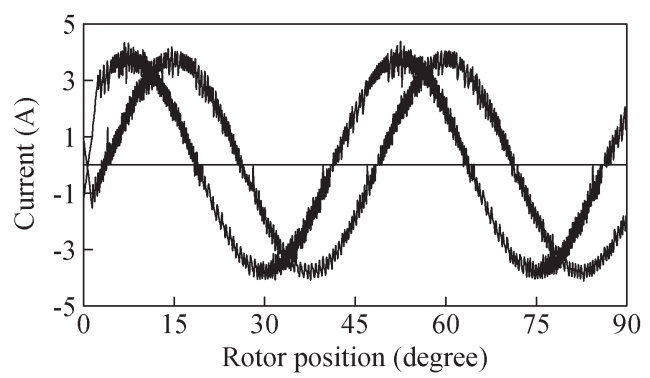

(a)

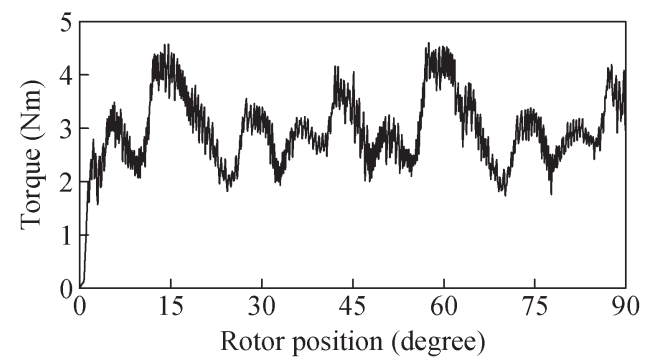

(b)

Fig. 10. Waveforms at remedial BLAC operation. (a) Current. (b) Torque.

due to inevitable variation between rectangular and sinusoidal pulsewidth-modulated currents.

In the event of the aforementioned open-circuit fault, the proposed remedial BLAC operation is activated. As shown in Fig. 10, there are two healthy current waveforms, and the resulting torque waveform seems to be comparable with that at normal BLDC operation. Quantitatively, the corresponding $T_{\text {av }}$ and $K_{T}$ are $2.98 \mathrm{~N} \cdot \mathrm{m}$ and $93.5 \%$, respectively. It verifies that the proposed remedial BLAC operation can maintain the same torque under the open-circuit fault. Increasingly, the corresponding torque ripple can be further improved, with $K_{T}$ reduced by $8.8 \%$.

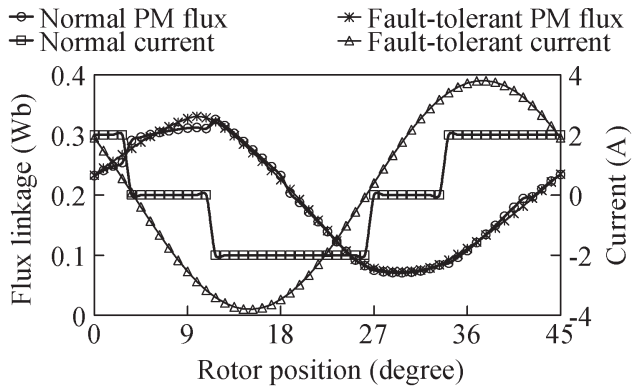

Fig. 11. PM flux linkage and current waveforms under normal BLDC and remedial BLAC operations.

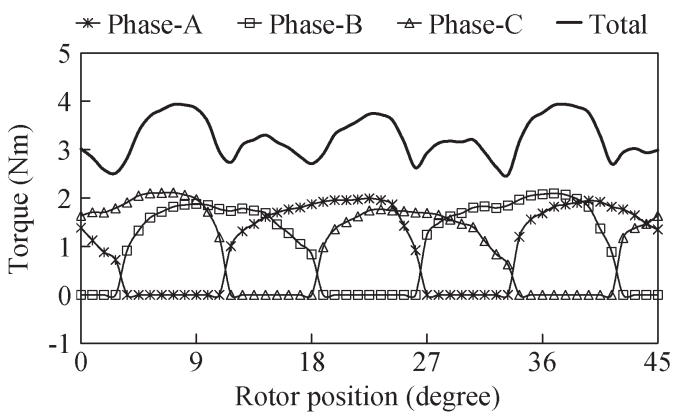

(a)

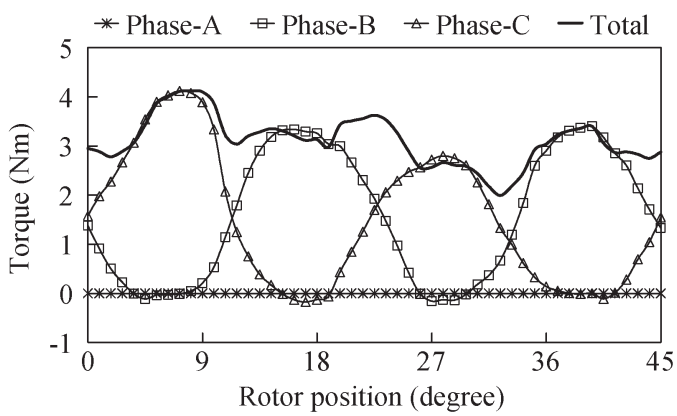

(b)

Fig. 12. Torque analysis. (a) Normal BLDC operation. (b) Remedial BLAC operation.

In order to closely investigate the generated torques of individual phases before and after the open-circuit fault, the phase currents are idealized as noise-free rectangular and sinusoidal waveforms under normal BLDC and remedial BLAC operations, respectively. As shown in Fig. 11, the corresponding PM flux-linkage waveforms (before and after fault) are almost the same. As aforementioned, the phase current waveform under the remedial BLAC operation is shifted forward. This angle shift causes the phenomena that a negative current is applied to a phase winding when its PM flux linkage is increasing and that a positive current is applied when the PM flux linkage is decreasing, leading to the creation of a periodic negative torque. Fig. 12 shows the torque waveforms generated by individual phases under normal BLDC and remedial BLAC operations, which confirms that periodic negative torque occurs at the remedial BLAC mode. Nevertheless, this negative torque is so small that it will not affect the overall average torque.

It should be noted that the current amplitude of the remedial BLAC operation is 1.9 times that of the normal BLDC operation, causing the corresponding rms current to increase 


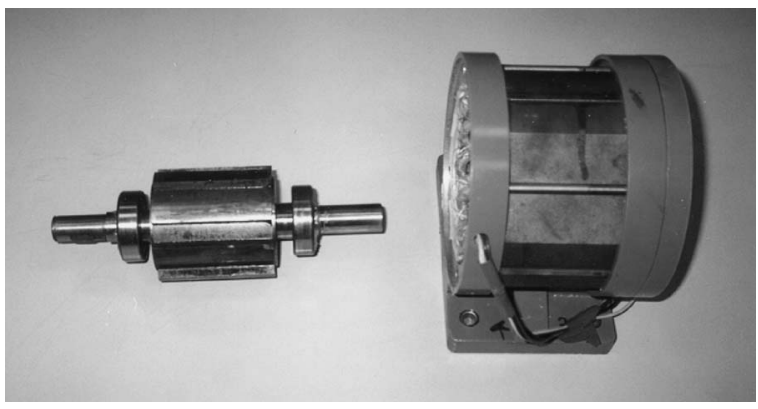

Fig. 13. Experimental DSPM motor.

TABLE I

MOTOR PARAMETERS

\begin{tabular}{ll}
\hline \hline Rated power $(\mathrm{kW})$ & 0.75 \\
Rated speed $(\mathrm{rpm})$ & 1500 \\
Rated torque $(\mathrm{Nm})$ & 4.77 \\
Rated current $(\mathrm{A})$ & 3 \\
Stator inner diameter $(\mathrm{mm})$ & 75 \\
Stack length $(\mathrm{mm})$ & 75 \\
Airgap length $(\mathrm{mm})$ & 0.45 \\
Stator pole number & 12 \\
Rotor pole number & 8 \\
Stator pole arc (degree) & 15 \\
Rotor pole arc (degree) & 20 \\
Stator pole height (mm) & 15 \\
Rotor pole height (mm) & 9 \\
Number of turns/phase & 260 \\
\hline \hline
\end{tabular}

by 1.6 times. Thus, the electric loading of the DSPM motor should take this effect into account during the design stage. Moreover, the copper loss of the two healthy phase windings during remedial BLAC operation is about 1.8 times that of the three-phase windings during normal BLDC operation, which inevitably reduces the efficiency. Nevertheless, such reduction in the designed electric loading and operating efficiency is the cost of fault-tolerant operation.

\section{EXPERIMENTAL RESUlTS}

An experimental three-phase 12/8-pole DSPM motor is prototyped as shown in Fig. 13. The key design data are listed in Table I. For the whole drive system, the maximum current value is $5 \mathrm{~A}$, the switching frequency is $20 \mathrm{kHz}$, and the dc-link voltage is $440 \mathrm{~V}$. Furthermore, an intelligent-powermodule-based converter and a DSP-based digital controller are built to drive the experimental motor. A separately excited dc generator is mechanically coupled to the DSPM motor and works as variable mechanical load. Since the DSPM motor drive is designed to normally operate in the BLDC mode, a lowcost low-resolution rotor position sensor is adopted.

First, the DSPM motor drive operates in the normal BLDC mode. The measured back-EMF waveform is shown in Fig. 14. It can be seen that this EMF waveform is trapezoidal, which agrees with the theoretical one shown in Fig. 2. Meanwhile, the measured three-phase current waveforms are shown in Fig. 15(a). As expected, these current waveforms are rectangular, which agree with the theoretical one shown in Fig. 2.

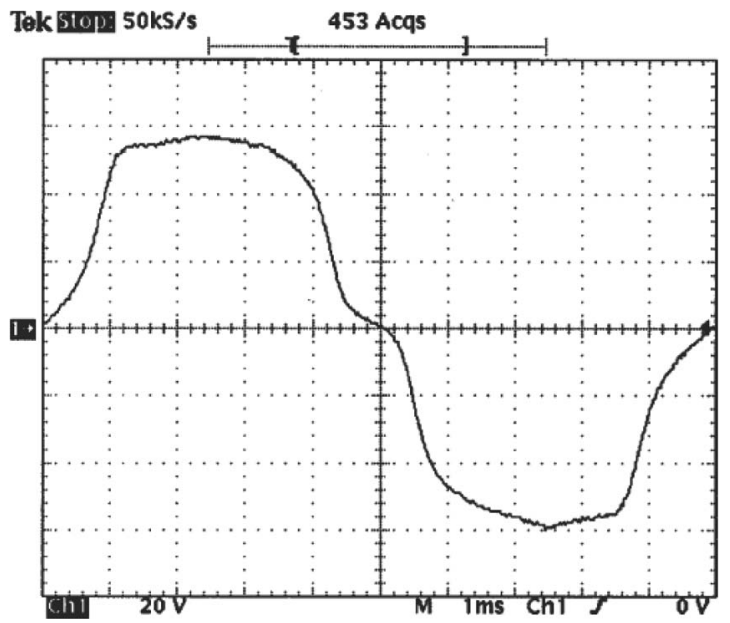

Fig. 14. Measured back-EMF waveform.

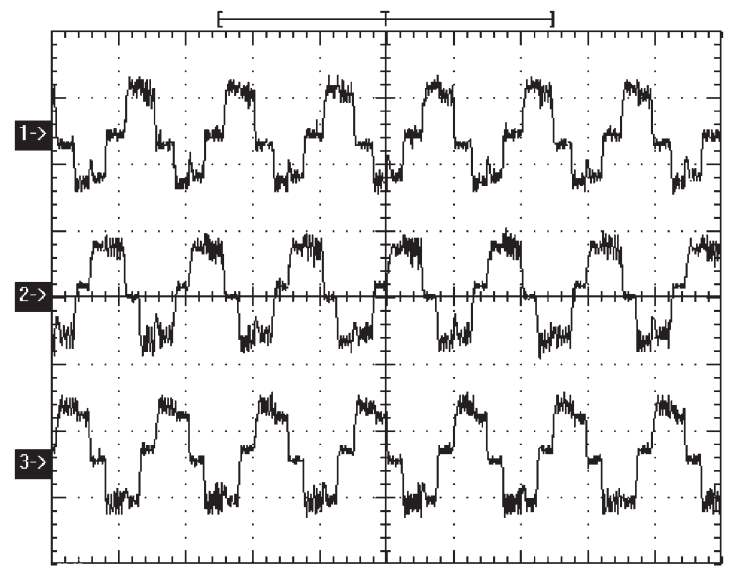

(a)

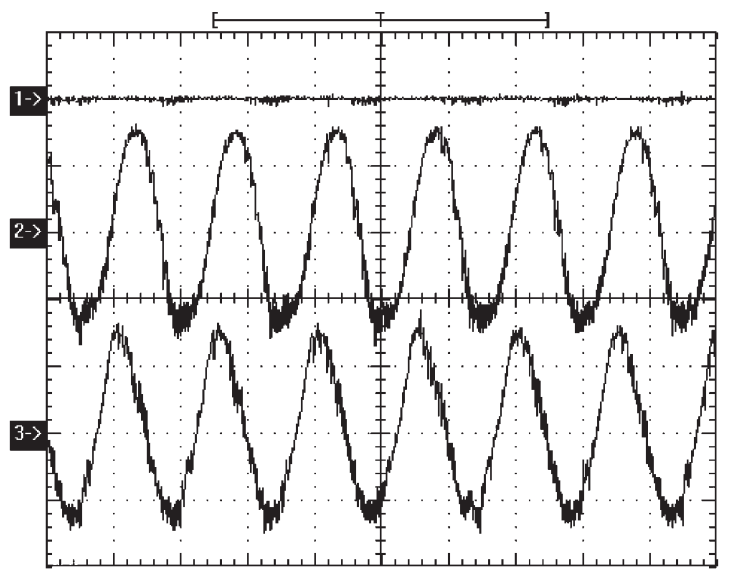

(b)

Fig. 15. Measured current waveforms $(10 \mathrm{~ms} / \mathrm{div}, 2.5 \mathrm{~A} / \mathrm{div})$. (a) Normal BLDC operation. (b) Remedial BLAC operation.

Furthermore, their magnitudes agree well with the simulated waveform shown in Fig. 7(a).

During the open-circuit fault with the loss of one phase, the DSPM motor drive operates in the remedial BLAC mode. The measured current waveforms are shown in Fig. 15(b). It can be seen that the current waveforms of the two healthy phases are sinusoidal, which agree with the theoretical ones, as shown 


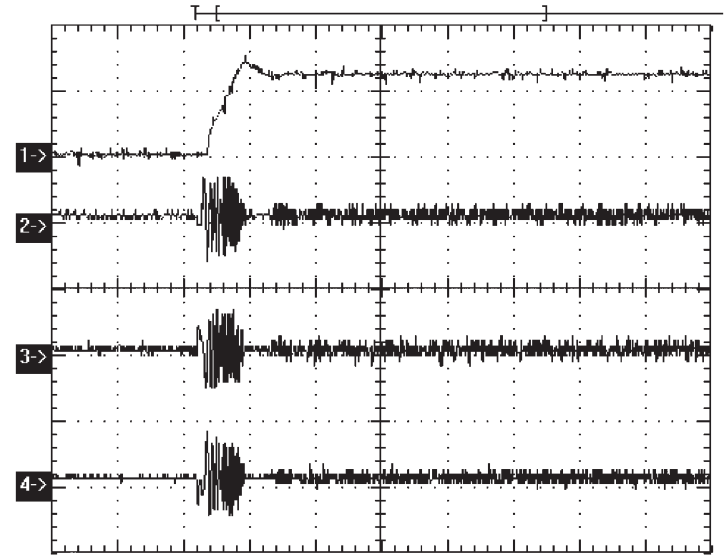

(a)

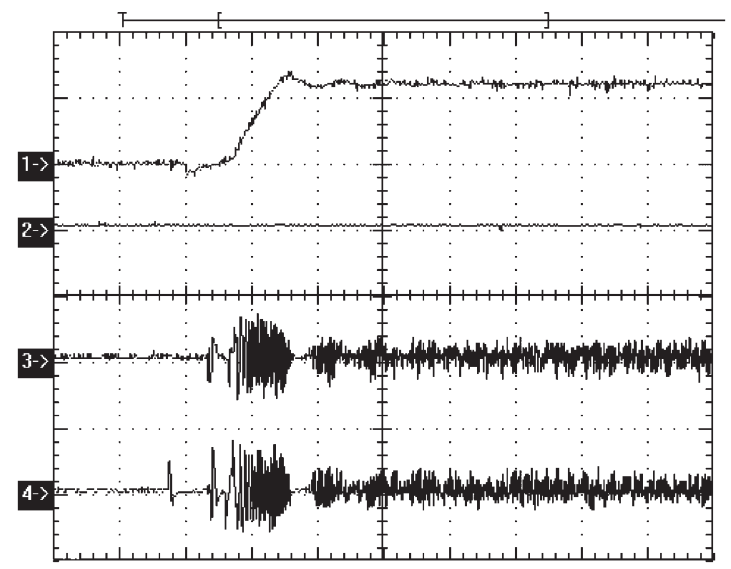

(b)

Fig. 16. Measured (trace 1) speed and (traces 2-4) current responses at startup (500 ms/div, $500 \mathrm{r} / \mathrm{min} / \mathrm{div}, 10 \mathrm{~A} / \mathrm{div})$. (a) Normal BLDC operation. (b) Remedial BLAC operation.

in Fig. 4. Furthermore, their amplitudes agree well with the simulated waveforms shown in Fig. 10(a).

In general, in order to reduce the cost, a low-resolution rotorposition sensor is adopted for the normal BLDC operation of the DSPM motor since only six commutation instants per cycle are required. However, the proposed remedial BLAC operation prefers to have a higher resolution of rotor position so that accurate synchronization can be maintained. Thus, with the use of a low-cost low-resolution rotor-position sensor, it can be observed that the fault-tolerant phase-current waveforms are not exactly sinusoidal, as shown in Fig. 15(b). It is expected and actually acceptable for fault-tolerant operation.

Finally, this paper aims to assess whether the DSPM motor drive can retain the self-starting capability under the opencircuit fault. Fig. 16(a) and (b) shows the startup responses under normal BLDC operation and remedial BLAC operation, respectively. It verifies that the motor drive can successfully perform self-starting under the open-circuit fault. On the other hand, it can be seen that the rise-up time of the motor drive with the remedial BLAC operation is longer than that with normal BLDC operation. It is expected because the starting currents under both operations are limited by the same maximum value while there are only two healthy phases producing the starting torque during the remedial operation.

\section{CONCLUSION}

In this paper, the remedial BLAC operation has been newly proposed and implemented for fault-tolerant DSPM motor drives. First, by equating the output torque between the normal BLDC operation and the BLAC operation, the torqueequivalent BLAC operation is resulted. Then, by equating the total MMF between the BLAC operation before fault and the BLAC operation after fault, the remedial BLAC operation can be derived. Both cosimulation and experimental results confirm that the proposed remedial BLAC operation can maintain the average torque, reduce the torque ripple, and retain the selfstarting capability under the open-circuit fault. This remedial BLAC operation is particularly important to enable fault tolerance for many practical applications such as electric vehicles.

\section{REFERENCES}

[1] S. Gopalakrishnan, A. M. Omekanda, and B. Lequesne, "Classification and remediation of electrical faults in the switched reluctance drive," IEEE Trans. Ind. Appl., vol. 42, no. 2, pp. 479-486, Mar./Apr. 2006.

[2] K. T. Chau, C. C. Chan, and C. Liu, "Overview of permanent-magnet brushless drives for electric and hybrid electric vehicles," IEEE Trans. Ind. Electron., vol. 55, no. 6, pp. 2246-2257, Jun. 2008.

[3] Z. Sun, J. Wang, D. Howe, and G. Jewell, "Analytical prediction of the short-circuit current in fault-tolerant permanent-magnet machines," IEEE Trans. Ind. Electron., vol. 55, no. 12, pp. 42108-44217, Dec. 2008.

[4] L. Max, J. Wang, K. Atallah, and D. Howe, "Real-time optimal torque control of fault-tolerant permanent magnet brushless machines," J. Appl. Phys., vol. 97, no. 10, pp. 10N 510-1-10N 510-3, May 2005.

[5] L. Parsa and H. A. Toliyat, "Fault-tolerant interior-permanent-magnet machines for hybrid electric vehicle applications," IEEE Trans. Veh. Technol., vol. 56, no. 4, pp. 1546-1552, Jul. 2007.

[6] S. Dwari and L. Parsa, "An optimal control technique for multiphase PM machines under open-circuit faults," IEEE Trans. Ind. Electron., vol. 55, no. 5, pp. 1988-1995, May 2008.

[7] M.-A. Shamsi-Nejad, B. Nahid-Mobarakeh, S. Pierfederici, and F. Meibody-Tabar, "Fault tolerant and minimum loss control of doublestar synchronous machines under open phase conditions," IEEE Trans. Ind. Electron., vol. 55, no. 5, pp. 1956-1965, May 2008.

[8] N. Bianchi, S. Bolognani, and M. D. Pre, "Impact of stator winding of a five-phase permanent-magnet motor on postfault operations," IEEE Trans. Ind. Electron., vol. 55, no. 5, pp. 1978-1987, May 2008.

[9] W. Hua, M. Cheng, Z. Q. Zhu, W. Zhao, and X. Kong, "Comparison of electromagnetic performance of brushless motors having magnets in stator and rotor," J. Appl. Phys., vol. 103, no. 7, pp. 07F 124-1-07F 124-3, Mar. 2008.

[10] M. Cheng, K. T. Chau, and C. C. Chan, "Design and analysis of a new doubly salient permanent magnet motor," IEEE Trans. Magn., vol. 37, no. 4, pp. 3012-3020, Jul. 2001.

[11] M. Cheng, K. T. Chau, and C. C. Chan, "New split-winding doubly salient permanent magnet motor drive," IEEE Trans. Aerosp. Electron. Syst., vol. 39, no. 1, pp. 202-210, Jan. 2003.

[12] K. T. Chau, Q. Sun, Y. Fan, and M. Cheng, "Torque ripple minimization of doubly salient permanent-magnet motors," IEEE Trans. Energy Convers., vol. 20, no. 2, pp. 352-358, Jun. 2005.

[13] C. Liu, K. T. Chau, J. Z. Jiang, and S. Niu, "Comparison of statorpermanent-magnet brushless machines," IEEE Trans. Magn., vol. 44, no. 11 , pp. 4405-4408, Nov. 2008.

[14] M. Cheng, Q. Sun, and E. Zhou, "New self-tuning fuzzy PI control of a novel doubly salient permanent-magnet motor drive," IEEE Trans. Ind. Electron., vol. 53, no. 3, pp. 814-821, Jun. 2006.

[15] W. Zhao, M. Cheng, X. Y. Zhu, W. Hua, and X. Kong, "Analysis of faulttolerant performance of a doubly salient permanent-magnet motor drive using transient cosimulation method," IEEE Trans. Ind. Electron., vol. 55, no. 4, pp. 1739-1748, Apr. 2008.

[16] K. T. Chau, M. Cheng, and C. C. Chan, "Performance analysis of 8/6-pole doubly salient permanent magnet motor," Elect. Mach. Power Syst., vol. 27, no. 10, pp. 1055-1067, Oct. 1999.

[17] M. Cheng, K. T. Chau, and C. C. Chan, "Static characteristics of a new doubly salient permanent magnet motor," IEEE Trans. Energy Convers., vol. 16, no. 1, pp. 20-25, Mar. 2001. 
[18] Z. Q. Zhu, J. X. Shen, and D. Howe, "Flux-weakening characteristics of trapezoidal back-EMF machines in brushless DC and AC modes," in Proc. CES/IEEE Int. Power Electron. Motion Control Conf., Shanghai, China, 2006, pp. 908-912.

[19] M. Khan and M. A. Rahman, "Development and implementation of a novel fault diagnostic and protection technique for IPM motor drives," IEEE Trans. Ind. Electron., vol. 56, no. 1, pp. 85-92, Jan. 2009.

[20] O. Poncelas, J. A. Rosero, J. Cusido, J. A. Ortega, and L. Romeral, "Motor fault detection using a Rogowski sensor without an integrator," IEEE Trans. Ind. Electron., vol. 56, no. 10, pp. 4062-4070, Oct. 2009.

[21] X. Zhu, M. Cheng, W. Zhao, C. Liu, and K. T. Chau, "A transient cosimulation approach to performance analysis of hybrid excited doubly salient machine considering indirect field-circuit coupling," IEEE Trans. Magn., vol. 43 , no. 6 , pp. $2558-2560$, Jun. 2007.

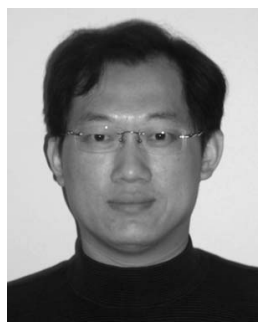

Wenxiang Zhao (M'08) was born in Jilin, China, in 1976. He received the B.Sc. and M.Sc. degrees in electrical engineering from Jiangsu University, Zhenjiang, China, in 1999 and 2003, respectively, and the Ph.D. degree in electrical engineering from Southeast University, Nanjing, China, in 2010.

Since 2003, he has been with the School of Electrical and Information Engineering, Jiangsu University, Zhenjiang, where he is currently an Associate Professor. From September 2008 to January 2009, he was a Research Assistant with the Department of Electrical and Electronic Engineering, The University of Hong Kong, Hong Kong. His areas of interest include electric-machine design, modeling, fault analysis, and intelligent control.

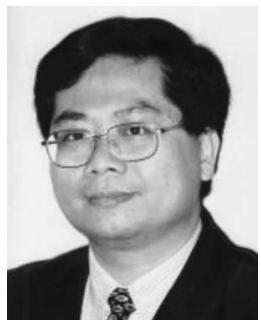

K. T. Chau (M'89-SM'04) received the first-class honors B.Sc.(Eng.), M.Phil., and Ph.D. degrees in electrical and electronic engineering from The University of Hong Kong, Hong Kong, in 1988, 1991, and 1993, respectively.

He is currently a Professor with the Department of Electrical and Electronic Engineering, The University of Hong Kong, where he is also the Director of the International Research Center for Electric Vehicles. His teaching and research interests focus on three main areas: electric vehicles, electric drives, and power electronics. In these areas, he has published over 300 refereed technical papers. He is also the coauthor of a monograph Modern Electric Vehicle Technology (Oxford University Press, 2001).

Dr. Chau is a Fellow of The Institution of Engineering and Technology. He was the recipient of the Outstanding Young Researcher Award in 2003, the University Teaching Fellowship Award in 2004, and the Award for Innovative Excellence in Teaching, Learning and Technology in 2005.

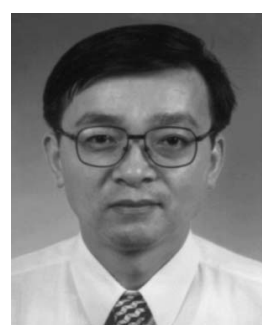

Ming Cheng (M'01-SM'02) received the B.Sc. and M.Sc. degrees from the Department of Electrical Engineering, Southeast University, Nanjing, China, in 1982 and 1987, respectively, and the Ph.D. degree from the Department of Electrical and Electronic Engineering, The University of Hong Kong, Hong Kong, in 2001

Since 1987, he has been with Southeast University, where he is currently a Professor in the School of Electrical Engineering, and the Director of the Research Center for Wind Power Generation. His teaching and research interests include electrical machines, motor drives for electric vehicles, and renewable energy generation. He has authored or coauthored over 200 technical papers and four books and is the holder of 23 patents in the aforementioned areas.

Dr. Cheng is a Fellow of The Institution of Engineering and Technology. He has served as Chair and Organizing Committee Member for many international conferences.

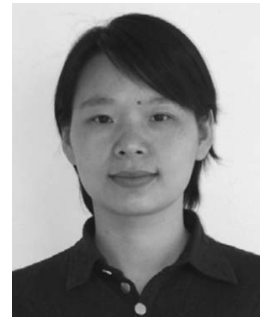

Jinghua Ji was born in Jiangsu, China, in 1977. She received the B.Sc., M.Sc., and Ph.D. degrees in electrical engineering from Jiangsu University, Zhenjiang, China, in 2000, 2003, and 2009, respectively.

Since 2000, she has been with the School of Electrical and Information Engineering, Jiangsu University, where she is currently a Lecturer. Her areas of interest include motor design and electromagnetic field computation.

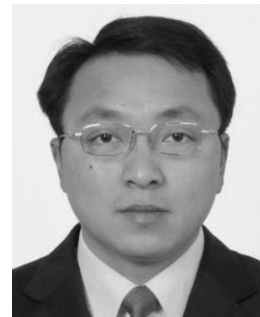

Xiaoyong Zhu (M'08) was born in Jiangsu, China, in 1975. He received the B.Sc. and M.Sc. degrees from Jiangsu University, Zhenjiang, China, in 1997 and 2002, respectively, and the Ph.D. degree from the School of Electrical Engineering, Southeast University, Nanjing, China, in 2008.

Since 1997, he has been with the School of Electrical and Information Engineering, Jiangsu University, where he is currently an Associate Professor. His areas of interest include motor drive and control, intelligent control, and power electronics. 